\title{
REFERENCE VALUES OF FACIAL FEATURES IN SCANDINAVIAN CHILDREN MEASURED WITH A RANGE-CAMERA TECHNIQUE
}

\author{
Kerstin Strömland, ${ }^{1}$ Yahua Chen, ${ }^{1}$ Tommy Norberg, ${ }^{2}$ Kristofer Wennerström ${ }^{1}$ and \\ Gregory Michael ${ }^{1}$ \\ From the ${ }^{1}$ Department of Clinical Neuroscience, Section of Paediatric Ophthalmology, Göteborg University \\ and ${ }^{2}$ Department of Mathematical Statistics, Chalmers University of Technology and \\ Göteborg University, Göteborg, Sweden
}

(Accepted for publication 26 January 1998)

\begin{abstract}
Reference values of facial features in white Scandinavian children were ascertained using a newly developed range-camera technique with a threedimensional measuring program specifically designed for anthropometric measurements. Seven facial features in 613 healthy subjects (322 girls, 291 boys), aged 1 month to 18 years, and nine subjects with the fetal alcohol syndrome, aged 7 to 18 years, were studied. Data were analysed by multivariate multiple regression and measurements of each facial feature plotted against age and presented as curves, with $95 \%$ and $99 \%$ univariate prediction limits. All children with fetal alcohol syndrome had shorter palpebral fissures, and in six of them the outer canthal distance was shorter than that in the reference group. The reference values presented may be useful in clinical practice - for example, in the evaluation of children with syndromes that result in dysmorphology of the face and in the planning of plastic and reconstructive surgery.
\end{abstract}

Key words: reference values, facial features, rangecamera technique, white Scandinavian children.

When dealing with congenital anomalies of the face it is necessary to distinguish abnormal morphological features from normal ones. Craniofacial anthropometry is a useful tool and allows the dysmorphologist to identify syndromes and the surgeon to plan reconstructive surgery. Different races and population groups, however, need their own reference values for evaluation of detailed facial structures. The present study was initiated to create reference values of multiple facial features in healthy white Scandinavian children of various ages. A new range-camera technique with a program that allows three-dimensional measurements, was used (16). To compare the facial features of the reference group with those of children with a dysmorphic syndrome, the fetal alcohol syndrome was chosen.

\section{PATIENTS AND METHODS}

\section{Patients}

A total of 613 healthy volunteers, 322 girls and 291 boys, age range 1 month to 18 years, and with parents of white Scandinavian origin only, were included in the study (Fig. 1). To establish a reference series representative of the target population of white Scandinavians the subjects were recruited from different sources in Göteborg, Sweden, such as daycare centres, schools, junior soccer teams, and outpatient clinics at the Children's Hospital. Children whose birth weight was less than $2500 \mathrm{~g}$, those who were premature (born before 37 weeks' gestation), and those with minor or major malformations or with disorders possibly associated with children's growth, were excluded.

Nine white Scandinavian children with the fetal alcohol syndrome, six girls and three boys aged 7-18 years, were compared with the reference group.

Written informed consent was obtained from the parents. The study was approved by the Committee for Ethics at the Medical Faculty, Göteborg University.

\section{Methods}

A range-camera technique, with a three-dimensional measuring program specifically designed for the quantitative analysis of various facial features, was used. A thorough description of the method, with assessment of the accuracy of the device and of the quality of the measurements, has been published (16). The range camera consists of a video-camera, a light projector, and a personal computer (Fig. 2). The video-camera captures a number of images of the face while it is being illuminated by different light patterns. From these, a three-dimensional "range image" is computed. Anatomical landmarks seen on 


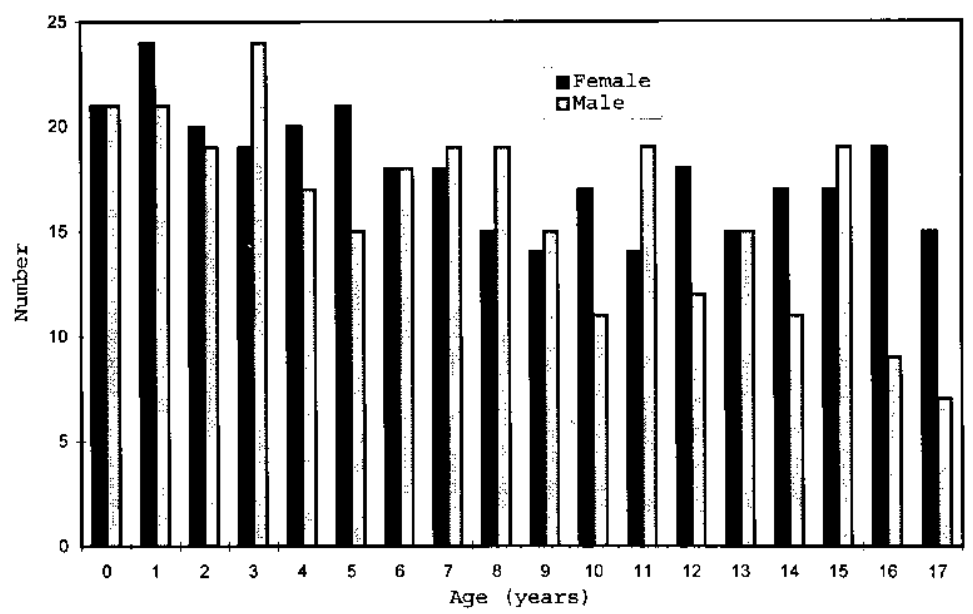

Fig. 1. Distribution by age of the 613 healthy white Scandinavian children studied.

the fully illuminated intensity image of the face are defined manually, and three-dimensional measurements are automatically obtained from the range image.

In the present study the dimensions of seven facial features were measured: the inner canthal distance (ICD), the outer canthal distance (OCD), the length of the right and left palpebral fissures (PFR, PFL), the length of the nose (LN) defined as the distance from the midpoint between the two inner canthi to the tip of the nose, the length of the upper lip (UL), and the length of the mouth (LM) (Fig. 3). In addition, the head circumference was measured with a tape.

The variables ICD, OCD, PFR, and PFL are interrelated. These variables were measured in a particular sequence (PFR, ICD, PFL, and OCD) to minimise the measurement error.

\section{Statistical methods}

Multivariate multiple regression was used to analyse the data. This makes it possible to predict the

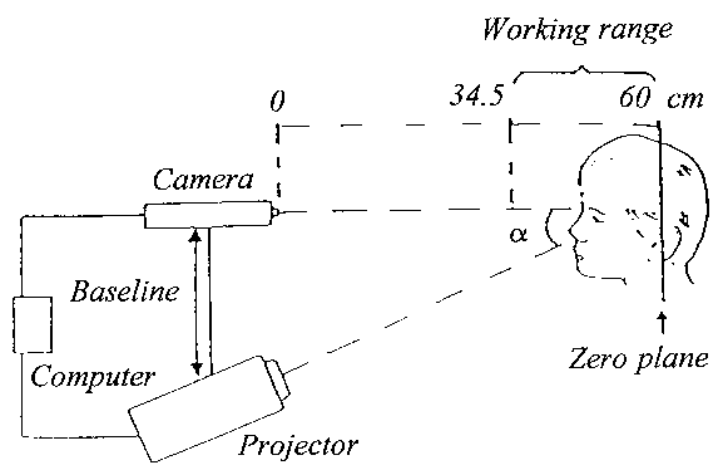

Fig. 2. Arrangement of the range-camera device. (From Strömland K, et al. Assessment of facial features with a range camera. Scand J Plast Reconstr Surg Hand Surg 1998; 32: 91-96 (16).) dimension of each facial feature from a knowledge of the child's age and sex. The $95 \%$ and $99 \%$ univariate prediction intervals were calculated for the seven facial features and for head circumference. These eight variables were fitted to the function

$$
y=a\left(x+x_{0}\right)^{b}
$$

where $y$ denotes any of the eight variables, $x$ represents the age of the child, and $\mathrm{x}_{0}$ is an age lag included in the model because growth begins before birth. One pair of variables ( $a$ and $b$ ), for each of the eight measurements and for each sex, is estimated in the regression.

To check the Gaussian assumption, a simultaneous $p$ value was calculated for each child and the ordered values were plotted. This $p$ value is a measure of how unusual the dimensions of the facial structures are

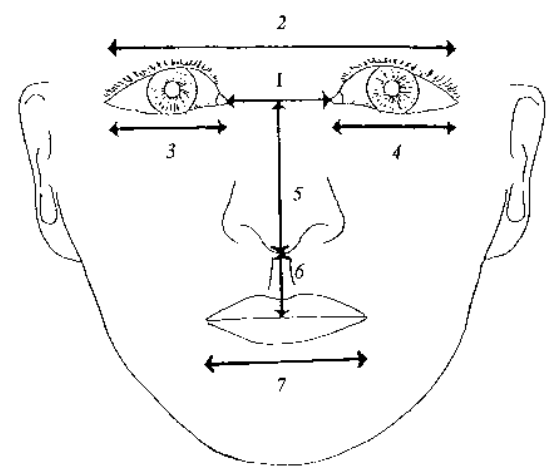

Fig. 3. Facial landmarks used for the measurements: $1=$ inner canthal distance, $2=$ outer canthal distance, $3=$ right palpebral fissure, $4=$ left palpebral fissure, $5=$ length of the nose, $6=$ length of the upper lip, and 7 = length of the mouth. (From Strömland K, et al. Assessment of facial features with a range camera. Scand J Plast Reconstr Surg Hand Surg 1998; 32: $91-$ 96 (16).) 
Table I. Estimation of the variables ( $a$ and $b$ ) for each facial feature and head circumference in girls and boys. $I C D=$ inner canthal distance, $O C D=$ outer canthal distance, $P F R=$ right palpebral fissure, $P F L=$ left palpebral fissure, $L N=$ length of nose, $U L=$ length of upper lip, and $L M=$ length of mouth

\begin{tabular}{llllll}
\hline & \multicolumn{2}{l}{ Girls } & & \multicolumn{2}{l}{ Boys } \\
\cline { 2 - 3 } \cline { 5 - 6 } & $\mathrm{a}$ & $\mathrm{b}$ & $\mathrm{a}$ & $\mathrm{b}$ \\
\hline ICD & 24.6383 & 0.078779 & & 24.5039 & 0.089241 \\
OCD & 62.1745 & 0.123354 & & 63.5157 & 0.122933 \\
PFR & 19.1232 & 0.141503 & & 19.4105 & 0.144262 \\
PFL & 18.9846 & 0.144514 & & 19.4429 & 0.142713 \\
LN & 20.8067 & 0.241754 & & 21.3676 & 0.236625 \\
UL & 13.9984 & 0.123480 & & 14.2163 & 0.152749 \\
LM & 29.4835 & 0.184181 & 30.0656 & 0.179660 \\
Head & 43.8769 & 0.084449 & & 44.3630 & 0.090727 \\
circum- & & & & \\
ference & & & & \\
\hline
\end{tabular}

compared with those of a normal face. The result was sufficiently close to a straight line to indicate that the assumption of a Gaussian distribution was correct. Moreover, plots of the residuals compared with age were made. They showed no systematic pattern that would suggest that the usual regression assumptions are not fulfilled.

A statistical hypothesis test was used to check the symmetry assumption that PFR $=$ PFL.

Facial measurements of the nine children with fetal alcohol syndrome were compared with measurements from the reference group. Combined $p$ values (partly simultaneous) were calculated for each of the two sets of variables (ICD, PFR, PFL, and head circumference) and (LN, UL, and head circumference), and also for all variables taken together.

\section{RESULTS}

Measurements of the facial features and head circumference of the reference group are plotted against age and presented as curves, with prediction values and $95 \%$ and $99 \%$ univariate prediction limits.

The age lag $\mathrm{x}_{0}$ was estimated to 0.93 , as this value gave the best overall fit. Table I lists the estimates of $\mathrm{a}$ and $\mathrm{b}$ for each facial feature and for head circumference in girls and boys. Fig. 4 shows the prediction values for all facial features of both sexes. Fig. $5 a-g$ shows the $95 \%$ and $99 \%$ univariate prediction limits as well as the

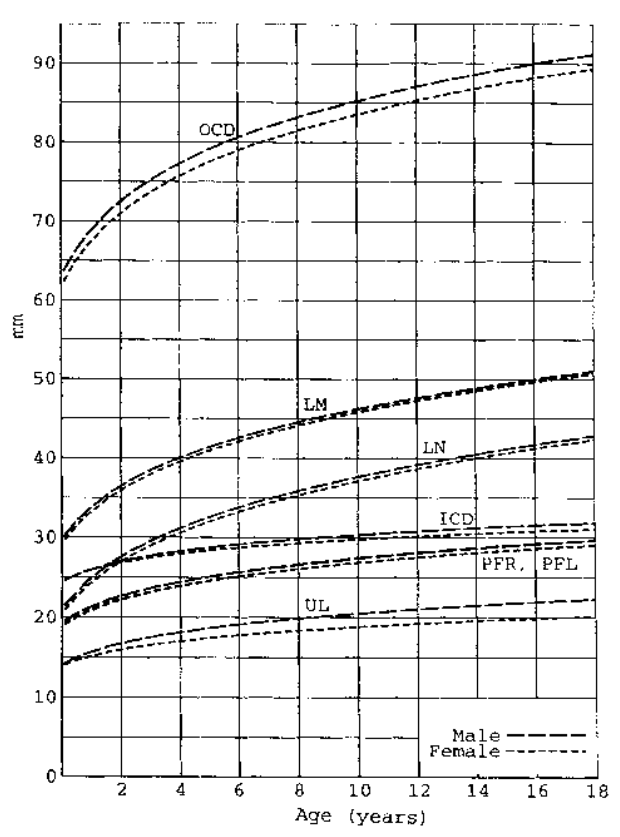

Fig. 4. Plots of prediction values for the measurements of seven facial features in 613 children. ICD $=$ inner canthal distance, $\mathrm{OCD}=$ outer canthal distance, $P F R=$ right palpebral fissure, $P F L=$ left palpebral fissure, $\mathrm{LN}=$ length of nose, $\mathrm{UL}=$ length of upper lip, and LM = length of mouth.

prediction values for the seven facial variables; Fig. $5 h$ gives the same curves for head circumference.

At all ages, all facial features of boys except the ICD were larger than those of girls. From birth to 1 year of age, the ICD of girls was larger than that of boys; thereafter that of boys was larger. Growth was fastest for OCD and slowest for ICD.

The $p$ value for rejecting the symmetry hypothesis PFR $=$ PFL was 0.22 .

Measurements of all seven facial features and head circumference and univariate $p$ values for children with fetal alcohol syndrome are shown in Table II. All children in this group had significantly shorter PFR and PFL than the reference group. Six of them also had a significantly shorter OCD, and four had a significantly smaller head circumference, compared with the reference group. No significant differences were found for ICD, LN, UL, and LM. Table II also shows the prediction values for 
Table II. Measurements, predictive values, and univariate $\mathrm{p}$ values for seven facial features and head circumference of children with fetal alcohol syndrome, and combined $\mathrm{p}$ values for the two sets of variables (ICD, PFR, PFL, and head circumference) and ( $L N, U L$, and head circumference) and $\mathrm{p}$ values for all variables assembled. ICD = inner canthal distance, OCD = outer canthal distance, $P F R=$ right palpebral fissure, $P F L=$ left palpebral fissure, $L N=$ length of nose, $U L=$ length of upper lip, and $L M=$ length of mouth. Distances were measured in $\mathrm{mm} . \quad(m v=$ measured value, tv = typical (predicted) value, $p v=$ univariate $\mathrm{p}$ value)

\begin{tabular}{|c|c|c|c|c|c|c|c|c|c|c|c|}
\hline $\begin{array}{l}\text { Case } \\
\text { No. }\end{array}$ & Sex & $\begin{array}{l}\text { Age } \\
\text { (year }\end{array}$ & & ICD & OCD & PFR & PFL & $\mathrm{LN}$ & UL & LM & $\begin{array}{l}\text { Head } \\
\text { circum } \\
\text { ference }\end{array}$ \\
\hline \multirow[t]{3}{*}{1} & $\mathrm{~F}$ & 7.6 & $m v$ & 32 & 72 & 20 & 21 & 33 & 19 & 31 & 49 \\
\hline & & & $t v$ & 29.2 & 81 & 25.9 & 25.9 & 35 & 18.2 & 43.8 & 52.6 \\
\hline & & & $p v$ & 0.20 & 0.02 & 0 & 0 & 0.5 & 0.74 & 0 & 0.03 \\
\hline \multirow[t]{3}{*}{2} & $\mathrm{~F}$ & 11.2 & $m v$ & 34 & 82 & 23 & 24 & 42 & 21 & 41 & 52 \\
\hline & & & $t v$ & 30 & 84.5 & 27.2 & 27.2 & 38 & 19 & 46.7 & 54.2 \\
\hline & & & $p v$ & 0.08 & 0.56 & 0.001 & 0.02 & 0.24 & 0.43 & 0.13 & 0.20 \\
\hline \multirow[t]{3}{*}{3} & $\mathrm{~F}$ & 12.9 & $m v$ & 29 & 75 & 23 & 23 & 34 & 22 & 44 & 50.5 \\
\hline & & & tv & 30.3 & 85.9 & 27.7 & 27.7 & 39.2 & 19.4 & 47.8 & 54.8 \\
\hline & & & $p v$ & 0.54 & 0.009 & 0 & 0.001 & 0.09 & 0.30 & 0.33 & 0.01 \\
\hline \multirow[t]{3}{*}{4} & $\mathrm{~F}$ & 13.5 & $m v$ & 27 & 70 & 21 & 21 & 35 & 20 & 44 & 53 \\
\hline & & & $t v$ & 30.4 & 86.4 & 27.9 & 27.9 & 39.7 & 19.5 & 48.2 & 55 \\
\hline & & & $p v$ & 0.1 & 0 & 0 & 0 & 0.14 & 0.83 & 0.28 & 0.25 \\
\hline \multirow[t]{3}{*}{5} & $\mathrm{~F}$ & 15.4 & $m v$ & 29 & 79 & 25 & 24 & 36 & 18 & 47 & 53 \\
\hline & & & $t v$ & 30.7 & 87.7 & 28.4 & 28.4 & 40.9 & 19.8 & 49.3 & 55.5 \\
\hline & & & $p v$ & 0.43 & 0.04 & 0.02 & 0.002 & 0.14 & 0.45 & 0.57 & 0.14 \\
\hline \multirow[t]{3}{*}{6} & $\mathrm{~F}$ & 15.5 & $m v$ & 34 & 83 & 25 & 25 & 38 & 22 & 45 & 53.5 \\
\hline & & & $t v$ & 30.7 & 87.8 & 28.4 & 28.4 & 40.9 & 19.8 & 49.4 & 55.6 \\
\hline & & & $p v$ & 0.16 & 0.28 & 0.02 & 0.02 & 0.39 & 0.39 & 0.28 & 0.24 \\
\hline \multirow[t]{3}{*}{7} & M & 7.0 & $m v$ & 30 & 70 & 20 & 20 & 30 & 19 & 38 & 47.5 \\
\hline & & & $t v$ & 29.5 & 82 & 26.2 & 26.1 & 34.9 & 19.5 & 43.6 & 53.5 \\
\hline & & & $p v$ & 0.81 & 0.003 & 0 & 0 & 0.08 & 0.83 & 0.11 & 0 \\
\hline \multirow[t]{3}{*}{8} & M & 15.6 & $m v$ & 32 & 82 & 24 & 25 & 40 & 19 & 48 & 54 \\
\hline & & & $t v$ & 31.5 & 89.7 & 29.1 & 29 & 41.5 & 21.8 & 49.8 & 57.2 \\
\hline & & & $p v$ & 0.82 & 0.09 & 0 & 0.006 & 0.67 & 0.26 & 0.67 & 0.07 \\
\hline \multirow[t]{3}{*}{9} & M & 18.0 & $m v$ & 29 & 81 & 26 & 25 & 36 & 20 & 42 & 52.5 \\
\hline & & & $t v$ & 31.9 & 91.2 & 29.7 & 29.6 & 42.9 & 22.3 & 51 & 57.9 \\
\hline & & & $p v$ & 0.19 & 0.02 & 0.01 & 0.002 & 0.04 & 0.38 & 0.02 & 0.002 \\
\hline
\end{tabular}

the children with fetal alcohol syndrome as well as the combined $p$ values for the two sets of variables (ICD, PFR, PFL, and head circumference) and (LN, UL, and head circumference), and the $p$ values for all eight variables assembled. All the children with fetal alcohol syndrome had a combined $p$ value for the set (ICD, PFR, PFL, and head circumference) of less than 0.03 and three had a combined $p$ value for (LN, UL, and head circumference) of less than 0.05. Seven of the nine children had $p$ values of less than 0.05 when all facial features and head circumference were considered together.

\section{DISCUSSION}

In this study, the fastest period of growth for all facial features in both sexes occurred during the first two years of life, which is in agreement with 
$p$ Value for

combined variables:

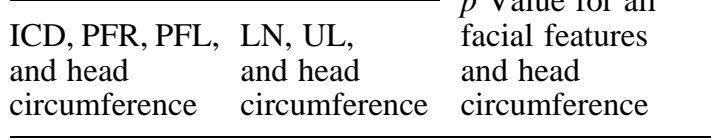

\begin{tabular}{lll}
0 & 0.16 & 0 \\
0.001 & 0.15 & 0.001 \\
0.002 & 0.04 & 0.01 \\
0 & 0.41 & 0 \\
0.02 & 0.22 & 0.18 \\
0.02 & 0.48 & 0.08 \\
0 & 0.002 & 0 \\
0.001 & 0.23 & 0.02 \\
0.003 & 0.006 & 0.02 \\
\hline
\end{tabular}

current reports $(6,10)$. The rate of growth then slowed down between 3 to 6 years of age, and after 7 years of age the growth was even slower.

To minimise the measurement error the interrelated variables ICD, OCD, PFR, and PFL were measured in the following sequence, starting at the right outer canthus: PFR, ICD, PFL, and OCD. This procedure reduced the number of changes of the mouse position and consequently the measurement error.

No significant difference was found in the measurements of the right and left palpebral fissures, which is in accordance with previous studies $(9,11-13,15)$.

The values of ICD in the present study confirm the results of Pryor (14) and Feingold and Bossert (9), but are lower than those of Farkas et al. (8). Our OCD values are in agreement with the data of Feingold and Bossert (9), but are slightly higher in all age groups compared with the results of Pryor (14). In children aged 1-3 years, Farkas et al. (8) found higher values for OCD than we did, but similar values in children over 3 years old. The values for the palpebral fissures (PF) were lower in our study than those of Farkas et al. (7). PF was lower from birth to 8 years of age than that reported by Tomas et al. (17), but was higher thereafter.

When the nine children with fetal alcohol syndrome were compared with the reference group, it was found that they generally had a shorter PF, which is in agreement with other studies (1-5). A shorter OCD was found in six children, which might be caused by the shorter palpebral fissures.

We think that the reference material presented is valuable and unique from several points of view. We collected data on facial features of a large number of subjects of all ages from birth to 18 years of age, representative of different stages of normal development. The series also provides a valuable database for measurements of additional facial structures in white Scandinavian children. The reference values of facial features will be used to facilitate the identification of syndromes with dysmorphic facial features and in the planning and follow-up of plastic and reconstructive surgery.

\section{ACKNOWLEDGEMENTS}

This work was supported by grants from the Wennergren Center Research Foundation, the Swedish Medical Research Council (Project No 10863), Friends of the Blind, Crown Princess Margareta's Association for Visually Handicapped, Crown Princess Lovisa's Association for Children's Care, and the Wilhelm and Martina Lundgren's Foundation 

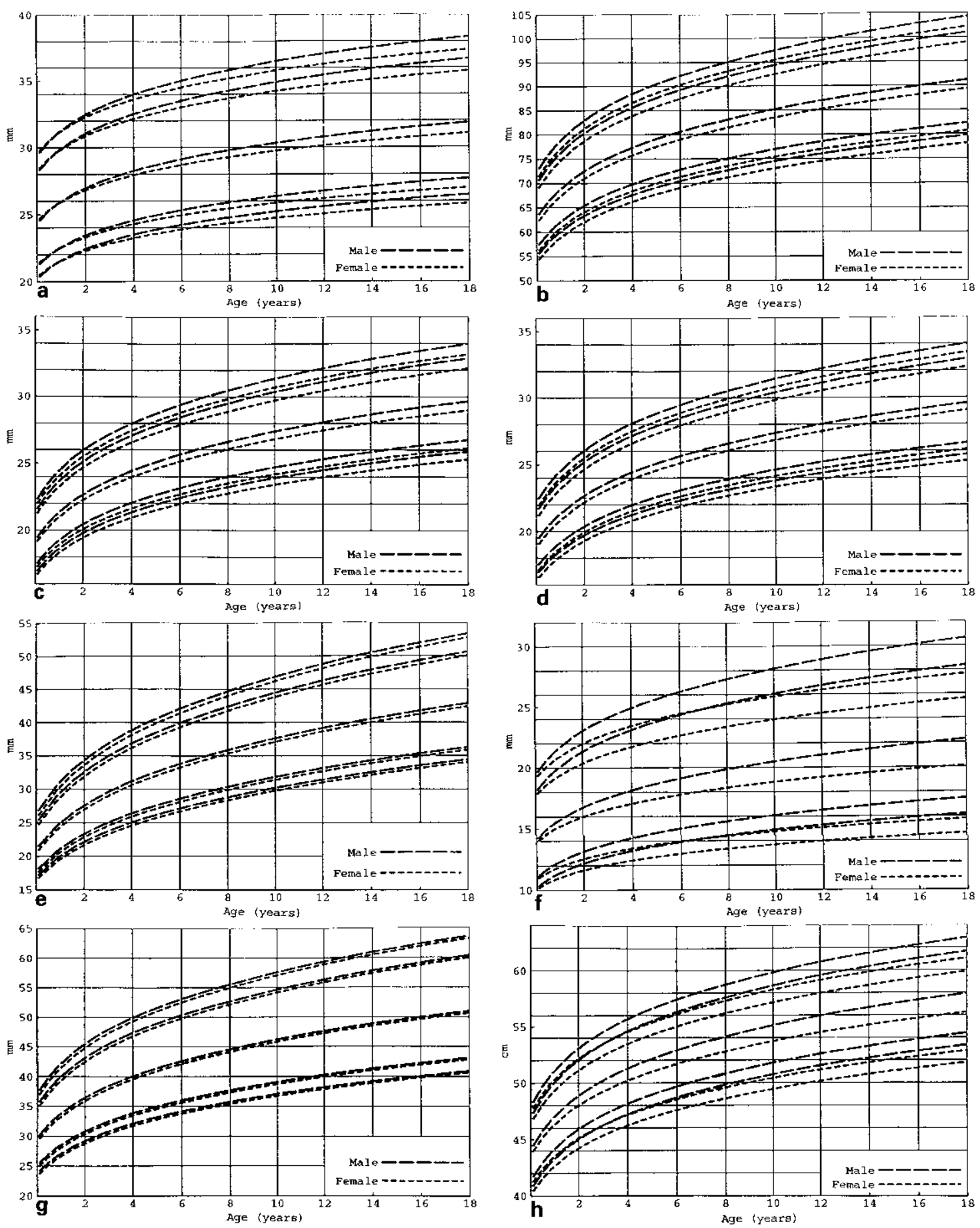

Fig. 5. Prediction values together with $95 \%$ and $99 \%$ univariate prediction limits, for the measurements of seven facial features and head circumference of 613 healthy children. A total of $5 \%$ of the study population have values outside the $95 \%$ limits, while $1 \%$ have values outside the $99 \%$ limits. These limits therefore coincide with 1.96 and $2.58 \mathrm{SD}$, respectively. The middle line indicates the prediction values. $(a)$ ICD, $(b)$ OCD, $(c)$ PFR, $(d)$ PFL, $(e) \mathrm{LN},(f) \mathrm{UL},(g) \mathrm{LM}$, and $(h)$ head circumference. ICD = inner canthal distance, $\mathrm{OCD}=$ outer canthal distance, $\mathrm{PFR}=$ right palpebral fissure, $\mathrm{PFL}=$ left palpebral fissure, $\mathrm{LN}=$ length of nose, $\mathrm{UL}=$ length of upper lip, and LM = length of mouth. 
for Medical Research. It was also supported by the Centre for Applied Mathematics and Statistics at Chalmers and Göteborg University. We are grateful to Pia Sundsten for her help.

\section{REFERENCES}

1. Abel EL, Martier S, Kruger M, Ager J, Sokol RJ. Ratings of fetal alcohol syndrome facial features by medical providers and biomedical scientists. Alcohol Clin Exp Res 1993; 17: 717-721.

2. Astley SJ, Clarren SK. A case definition and photographic screening tool for the facial phenotype of fetal alcohol syndrome. J Pediatr 1996; 129: 33-41.

3. Astley SJ, Clarren SK. A fetal alcohol syndrome screening tool. Alcohol Clin Exp Res 1995; 19: 1565-1571.

4. Astley SJ, Clarren SK, Little RE, Sampson PD, Daling JR. Analysis of facial shape in children gestationally exposed to marijuana, alcohol and/ or cocaine. Pediatrics 1992; 89: 67-77.

5. Clarren SK, Sampson PD, Larsen J et al. Facial effects of fetal alcohol exposure: assessment by photographs and morphometric analysis. Am J Med Genet 1987; 26: 651-666.

6. Farkas LG. Anthropometry of the head and face. 2nd ed. New York: Raven Press, 1994: 89-102.

7. Farkas LG, Hreczko TA, Katic MJ. In: Farkas LG, ed. Anthropometry of the head and face. 2nd ed. New York: Raven Press, 1994: 273.

8. Farkas LG, Posnick JC, Hreczko TM, Pron GE. Growth patterns in the orbital region: a morphometric study. Cleft Palate Craniofac J 1992; 29: 315-318.

9. Feingold M, Bossert WH. Normal values for selected physical parameters: an aid to syndrome delineation. In: Bergsma D, Paul NW, eds. Birth defects: original article series. New York: The National Foundation, 1974; 10: 1-16.

10. Hall JG, Froster-Iskenius UG, Allanson JE. Handbook of normal physical measurements. Oxford: Oxford University Press, 1989: 139-193.

11. Iosub S, Fuchs $M$, Bingol N, Stone RK, Gromisch DS, Wasserman E. Palpebral fissure length in black and Hispanic children: correlation with head circumference. Pediatrics 1985; 75: 318-320.

12. Jones KL, Hanson JW, Smith DW. Palpebral fissure size in newborn infants. Pediatrics 1978; 92: 787.

13. Osuobeni EP, Al-Ibraheem AM. Ocular and facial dimensions of male Arab children. J Am Optom Assoc 1993; 64: 717-722.

14. Pryor HB. Objective measurement of interpupillary distance. Pediatrics 1969; 44: 973-977.

15. Sivan Y, Merlob P, Reisner SH. Eye measurements in preterm and term newborn infants. $J$ Craniofac Genet Dev Biol 1982; 2: 239-242.

16. Strömland K, Chen Y, Michael G, Svensson E, Gustavsson T. Assessment of facial features with a range camera. Scand J Plast Reconstr Surg Hand Surg 1998; 32: 91-96.

17. Tomas IT, Gaitantzis YA, Frias JL. Palpebral fissure length from 29 weeks' gestation to 14 years. Clinical and laboratory observations. J Pediatrics 1987; 2: 267-268.

Correspondence to:

Kerstin Strömland, MD, PhD

Department of Paediatric Ophthalmology

Sahlgrenska University Hospital/Östra

SE 41685 Göteborg

Sweden 
Copyright of Scandinavian Journal of Plastic \& Reconstructive Surgery \& Hand Surgery is the property of Taylor \& Francis Ltd and its content may not be copied or emailed to multiple sites or posted to a listserv without the copyright holder's express written permission. However, users may print, download, or email articles for individual use. 